\title{
Psychotropic Polypharmacy Among Children and Youth Receiving Medicaid, 2012-2015
}

\author{
W. David Lohr, MD; Liza Creel, PhD, MPH; Yana Feygin, MS; Michelle Stevenson, MD, MS; \\ Michael J. Smith, MD, MSCE; John Myers, PhD, MPH; Charles Woods, MD, MS; Gil Liu, MD, MS; \\ and Deborah Winders Davis, PhD
}

\begin{abstract}
BACKGROUND: The rates of mental health diagnoses in children have increased. Children in poverty have the highest rates. The use of psychotropic medication for children has been increasing, which is concerning because of the unknown long-term effects and the increased burden on the health care system. The state of Kentucky ranks among the highest in the United States for children with mental health problems, children living in poverty, and children receiving psychotropic medication.

OBJECTIVE: To examine recent trends and determinants of interclass psychotropic polypharmacy (PP) use for children and youth receiving Medicaid to inform intervention development.
\end{abstract}

METHODS: A retrospective cohort study was conducted using 2012-2015 Kentucky Medicaid claims for children aged 0-17 years, with continuous enrollment for $\geq 90$ days with at least 1 behavioral health diagnosis $(\mathrm{N}=237,393)$. Interclass PP was defined as the presence of at least 2 psychotropic medication prescription fills for at least 2 different classes of medication that, if taken as directed, would be used concurrently for at least 90 consecutive days (allowing for a single 15-day lag). The outcome variables were the presence of any interclass PP and the number of months a child received interclass PP. We conducted a descriptive analysis and developed 2 separate generalized linear regression models to test for associations between individual characteristics of children treated with psychotropic medication for $\geq 90$ days $(n=75,639)$ and each outcome of interest.

RESULTS: For the sample of children with at least 90 days of psychotropic medication treatment, $38 \%$ had at least 3 covered months of PP over the 4 years studied. Children in foster care received alpha agonists (116 vs. 69 per 1,000 children) or antidepressants ( 225 vs. 176 per 1,000$)$ at a higher rate than other children receiving Medicaid but received stimulants at a lower rate (403 vs. 638 per 1,000). The primary 2-drug class combinations were stimulants with either alpha agonists or antidepressants. Children in foster care $(0 \mathrm{R}=1.7,95 \% \mathrm{Cl}=1.58,1.84, P<0.001)$, with a bipolar disorder ( $0 \mathrm{R}=2.24,95 \% \mathrm{Cl}=2.10,2.38, P<0.001)$, mood disorder not otherwise specified $(0 \mathrm{R}=1.11,95 \% \mathrm{Cl}=1.04,1.17, P<0.001)$, or autism spectrum disorders $(\mathrm{OR}=1.17,95 \% \mathrm{Cl}=1.08,1.26, P<0.001)$ had increased the odds of ever receiving PP. Black children had lower odds $(\mathrm{OR}=0.72,95 \% \mathrm{Cl}=0.67$, $0.77, P<0.001$ ) of ever receiving PP. Children aged $6-11$ years (beta $=3.08$, $95 \% \mathrm{Cl}=2.87,3.29$ ) and $12-17$ years (beta $=1.61,95 \% \mathrm{Cl}=1.38,1.83$ ) had more covered months with PP compared with those aged $0-5$ years. Black children had fewer covered months of PP compared with white children (beta $=-1.36,95 \% \mathrm{Cl}=-1.61,-1.11]$. Children in foster care (beta $=1.83$, $95 \% \mathrm{Cl}=1.53,2.13$ ) had more covered months with PP. Children residing in nonurban areas had fewer months with $\mathrm{PP}$ (beta $=-0.4,95 \% \mathrm{Cl}=-0.54$, -0.26) compared with those residing in urban areas, as did those children with depression (beta $=-3.32,95 \% \mathrm{Cl}=-3.55,-3.1$ ), impulse control disorder (beta $=-2.07,95 \% \mathrm{Cl}=-2.28,-1.85$ ), and conduct disorder (beta $=-1.34$, $95 \% \mathrm{Cl}=-1.64,-1.05)$. Children with bipolar disorder (beta $=3.62,95 \%$ $\mathrm{Cl}=3.38,3.86$ ) and autism (beta $=2.04,95 \% \mathrm{Cl}=1.75,2.33$ ) had more covered months with PP. As comorbidity increased, the duration of PP treatment increased (beta $=2.49,95 \% \mathrm{Cl}=2.36,2.62$ ).

CONCLUSIONS: The rates of PP are concerning, especially for children in foster care and children aged 6-11 years. Efforts to safeguard medication use are needed, as well as future exploration of racial differences in PP.

J Manag Care Spec Pharm. 2018;24(8):736-44

Copyright $\odot$ 2018, Academy of Managed Care Pharmacy. All rights reserved.

\section{What is already known about this subject}

The use of psychotropic medication for the treatment of mental health problems in children and youth is increasing.

Mental disorders are among the costliest conditions treated in children.

There has been an increase in the number of youth receiving more than 1 psychotropic medication or polypharmacy.

\section{What this study adds}

This study used a large, statewide analysis of 2012-2015 Kentucky Medicaid claims and found a high rate of psychotropic polypharmacy among children, especially school-age children and those in foster care.

Recent data were used that included children aged 0-17 years and reported psychotropic polypharmacy by race from a state that ranks among the highest for psychotropic medication use.

A t some point during childhood, 1 in 5 U.S. children is diagnosed with a mental health disorder, with children from low-income families disproportionately affected. ${ }^{1}$ The combined medical burden, functional impairments, and decreased productivity of those with mental health disorders among U.S. children and youth aged under 24 years cost an estimated $\$ 250$ billion per year. As such, mental disorders are among the costliest conditions treated in children. ${ }^{2}$

The use of psychotropic medication for the treatment of mental health problems in children and youth is increasing, doubling in frequency as the primary management strategy between 1995 and 2010. ${ }^{3}$ The cost of pharmacologic treatment of children with mental health and/or behavioral problems is an important part of Medicaid expenditures. ${ }^{4-6}$ In addition to 
concerns regarding the fiscal and social burdens associated with childhood mental illness, questions remain about the long-term safety and efficacy of psychotropic medication use for children, especially young children; children receiving antipsychotics; and children receiving multiple medications. ${ }^{7,8}$

Previous studies suggest that there has been an increase in the numbers of youth receiving psychotropic polypharmacy (PP), that is, simultaneous treatment with more than 1 psychotropic medication) ${ }^{7,9-12}$ Previous studies of PP used data from 2008 or earlier, ${ }^{9,10,12-14}$ are from non-U.S. countries, ${ }^{11}$ have small sample sizes, ${ }^{10}$ do not include children aged less than 6 years, ${ }^{10,13,14}$ and do not include data on race and/or ethnicity. ${ }^{10-14}$ More research is needed to better understand current trends, especially in states such as Kentucky, which have more children than the national average with mental health disorders, more children living in poverty, and more children receiving psychotropic medication. . $^{3,5,15,16}$

The benefit versus risk of PP in children remains unclear. While a few pilot studies exist, there is little robust evidence that supports the use of PP for children and youth. ${ }^{7,9,14}$ In a systematic review of the use of antipsychotics and stimulants in children with attention-deficit/hyperactivity disorder (ADHD) and disruptive behavior disorders, there was no evidence of PP superiority compared with monotherapy, while concerns were documented regarding the use of polypharmacy. ${ }^{8}$ PP for other diagnoses were not examined. The authors concluded that the evidence supporting combination therapy was limited by the heterogeneity of the samples, the small sample sizes, and the lack of placebo controls or comparisons with other therapies. The authors also raised concerns regarding the adverse effects, including metabolic risks, but concluded that more rigorously designed studies were needed to establish benefit and evaluate potential increases in risk for adverse events. ${ }^{8}$ Another study has reported increased risk associated with PP when atypical antipsychotic medication is combined with antidepressants, resulting in increased risk of type 2 diabetes mellitus. ${ }^{17}$

Previous studies have suggested that older male children and children with multiple mental health diagnoses on public insurance and in foster care are more likely to receive PP..$^{18,19}$ Unfortunately, these studies were single institution studies that did not use large representative databases. Our study, however, used a database consisting of all medical and pharmacy claims for children receiving Kentucky Medicaid benefits over a 4-year period. We developed models to test for factors associated with receipt of interclass PP and the duration of time in months on polypharmacy for children receiving Kentucky Medicaid.

Kentucky ranks higher than the national average in the prevalence of mental health problems and rates of psychotropic medication use but lower than the national average in the proportion of children receiving mental health services..$^{20,21}$ This concerning pattern has raised questions about the use of PP for children receiving Kentucky Medicaid. The goal of this

\section{FIGURE 1 Description of Sample Inclusion for} Kentucky Medicaid Claims

Children aged $0-17$ years with $\geq 90$ days continuous enrollment and at least 1 behavioral health diagnosis of interest $\mathrm{N}=237,393$

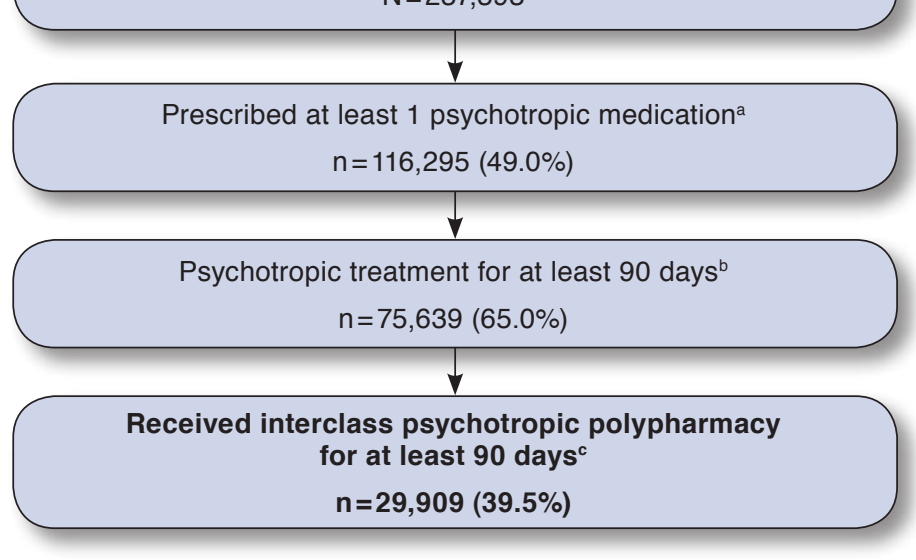

Including prescriptions for antidepressants, anxiolytics, antipsychotics, stimulants, and alpha agonists.

${ }^{b}$ Psychotropic treatment was defined as having at least 1 psychotropic medication prescription for at least 90 days (allowing for a single 15-day break in refills) during the study period.

Interclass psychotropic polypharmacy was defined as the presence of at least 2 psychotropic medication prescription fills for at least 2 different classes of medication that, if taken as directed, would be used at the same time for at least 90 consecutive days (allowing for a single 15-day break in refills) during the study period.

study was to identify the epidemiology of PP use and measure determinants, such as demographic information and diagnostic groups, to evaluate factors that independently predict treatment and duration of treatment with interclass PP for children receiving Kentucky Medicaid services.

\section{Methods}

\section{Data Source and Sample}

Data were extracted from Kentucky Medicaid claims records from 2012-2015 (Figure 1). These data included information on all health services billed through Kentucky Medicaid insurance (service date, type, location, provider, and associated International Classification of Diseases, Ninth/Tenth Revision, Clinical Modification [ICD-9/10-CM] codes), as well as patient demographic information such as date of birth, gender, selfidentified race, and postal code for all enrollees. We developed a detailed dataset for a cohort of children aged 0-17 years with continuous enrollment for $\geq 90$ days and at least 1 behavioral health diagnosis of interest $(\mathrm{N}=237,393$; see Appendix A for diagnoses, available in online article). Two separate polypharmacy outcomes were then assessed for each included child: (1) any instance of interclass PP, calculated as a binary variable where 1 equaled polypharmacy at any time across the 
study period and zero indicated no polypharmacy, and (2) the length of time in months that a child had interclass PP. For our descriptive analysis, we further reduced the sample to children treated with psychotropic medication for $\geq 90$ days $(\mathrm{n}=75,639)$ and removed children with any seizure disorders for our regressions $(n=67,827)$, since many of the drugs of interest may also be used as antiepileptics.

\section{Definition of PP}

Interclass PP was defined as the presence of at least 2 psychotropic medication prescription fills for at least 2 different classes of medication that, if taken as directed, would be used at the same time for at least 90 consecutive days (allowing for a single 15-day lag in getting a prescription refilled) during the study period. There were 2 outcomes of interest: the presence of any interclass PP and the length of time in months that a child received interclass psychotropic medication polypharmacy.

\section{Diagnostic Categories}

Psychiatric diagnoses were identified by an ICD-9/10-CM code for a psychiatric disorder in any of the 4 available diagnostic code columns on either the inpatient or outpatient claims (Appendix A). Psychiatric diagnoses were categorized as follows: mood disorders (which included major depressive disorder and other depressive disorders), mood disorder not otherwise specified, disruptive mood dysregulation disorder (DMDD), and bipolar disorder. Autism spectrum disorders (ASD) and pervasive developmental disorders (PDD) were separate categories as were sleep-wake disorders. An additional variable was created to count the number of psychiatric categories with which each child was diagnosed to measure comorbidities.

\section{National Drug Code Numbers}

Dispensed psychiatric medications (Appendix B, available in online article) were identified by National Drug Code numbers in pharmacy claims for the following 6 medication categories: (1) antidepressants (selective serotonin reuptake inhibitors, serotonin and norepinephrine reuptake inhibitors, tricyclics, monoamine oxidase inhibitors, and miscellaneous); (2) anxiolytics (benzodiazepines and miscellaneous); (3) antipsychotics (typical, atypical, and miscellaneous); (4) stimulants (including atomoxetine); (5) mood stabilizers; and (6) alpha agonists.

\section{Covariates}

We obtained the following covariate data on all subjects: age, gender, race, location, foster care, presence of seizures/stroke, and the presence of psychosocial therapy claims per year. Age, gender, race, and foster care status were provided by yearly enrollment data files from Kentucky Medicaid. Given the multiyear study period, covariates were measured at the time the children enrolled in Medicaid, with the exception of age, which was calculated as the maximum age during the study period. Metropolitan and nonmetropolitan geography was determined using 2013 Rural-Urban Continuum Codes (RUCC), as defined by the U.S. Department of Agriculture. Geography for each child was coded as metropolitan when the county of residence had an RUCC code of 1-3 and as nonmetropolitan when the county of residence had an RUCC code of 4-9. The presence of seizures/stroke at any point during each year was identified by at least 1 ICD-9/10-CM code in any position for seizures, cerebrovascular disease, or convulsive disorders. The total number of enrolled months was also calculated to control for total time that a child was covered by Kentucky Medicaid.

\section{Statistical Analysis}

We performed descriptive analyses to summarize the characteristics of our sample, using ANOVA and chi-square tests to assess differences in demographic variables for continuous and categorical variables, respectively. Estimates of interclass PP prevalence were calculated using all eligible subjects as the denominator $(n=75,639)$.

Two separate statistical models were specified for this study. The first used a generalized linear model with a logit link and binomial distribution to assess factors associated with any presence of interclass PP for the study population. A second separate generalized linear model with an identity link and Gaussian distribution was developed for predicting length of interclass PP treatment for the full cohort of children over the 4 years.

Each outcome of interest was tested as a function of the covariates previously discussed, allowing us to test for significant predictors of a child ever having interclass PP and the length of interclass PP. Odds ratios were reported for the regression model that assessed individual characteristics associated with having any instance of polypharmacy during the study period. Beta coefficents were reported with 95\% confidence intervals [CIs] and 2-sided $P$ values for length of time in months that a child was treated with polypharmacy. A 2-tailed $P$ value of $<0.05$ was considered statistically significant. The beta coefficients were interpreted as the change in the number of months of polypharmacy given a 1-unit change in the covariate. We performed data preparation and analyses using R statistical software, version 3.4.0 (R Foundation for Statistical Computing, Vienna, Austria)

The study was approved by the Institutional Review Board at the University of Louisville. Data were obtained from the Kentucky Department of Medicaid Services, which approved the use for this study.

\section{Results}

Over the 4 years of this study, 237,393 children were continuously enrolled for $\geq 90$ days in Kentucky Medicaid. Of these, 75,639 (31.8\%) were dispensed at least 1 psychotropic 


\begin{tabular}{|c|c|c|c|}
\hline \multicolumn{4}{|c|}{$\begin{array}{l}\text { Demographic and Clinical } \\
\text { Characteristics of Children with } \\
\text { Interclass PP Enrolled in Kentucky } \\
\text { Medicaid and Treated with at Least } \\
90 \text { Days of Psychotropic Medications }\end{array}$} \\
\hline 2012-2015 & Total & $\begin{array}{c}\text { Interclass } \\
\mathrm{PP}, \mathrm{n}\end{array}$ & $\begin{array}{c}\text { Interclass } \\
\text { PP, \% }\end{array}$ \\
\hline Total on psychotropic medications ( $\geq 90$ days) & 75,639 & 29,900 & 39.5 \\
\hline \multicolumn{4}{|l|}{ Age category } \\
\hline $0-5$ years & 12,242 & 3,928 & 32.1 \\
\hline $6-11$ years & 33,466 & 14,131 & 42.2 \\
\hline $12-17$ years & 29,931 & 11,850 & 39.6 \\
\hline Foster care & 4,504 & 2,821 & 62.6 \\
\hline \multicolumn{4}{|l|}{ Gender } \\
\hline Male & 47,185 & 19,795 & 42.0 \\
\hline Female & 28,454 & 10,114 & 35.6 \\
\hline \multicolumn{4}{|l|}{ Race } \\
\hline Black & 6,501 & 2,229 & 34.3 \\
\hline White & 50,592 & 18,905 & 37.4 \\
\hline Other & 2,109 & 727 & 34.5 \\
\hline Not provided & 16,437 & 8,048 & 49.0 \\
\hline Psychosocial therapy & 44,907 & 21,689 & 48.3 \\
\hline Anxiety and trauma-related disorders & 32,782 & 15,483 & 47.2 \\
\hline Autism and PDD NOS & 7,281 & 4,541 & 62.4 \\
\hline ADD & 58,946 & 25,962 & 44.0 \\
\hline ODD & 19,307 & 11,553 & 59.8 \\
\hline Conduct disorders & 6,209 & 3,877 & 62.4 \\
\hline Mood disorders total & 31,357 & 16,763 & 53.5 \\
\hline Depression & 19,234 & 8,967 & 46.6 \\
\hline Bipolar disorder & 8,771 & 6,411 & 73.1 \\
\hline Disruptive mood/dysregulation disorder & 4,523 & 3,116 & 68.9 \\
\hline Mood disorder NOS & 18,644 & 11,870 & 63.7 \\
\hline Impulse control & 18,537 & 9,936 & 53.6 \\
\hline Other mental health disorders & 14,632 & 8,198 & 56.0 \\
\hline Other NDD & 20,626 & 9,922 & 48.1 \\
\hline Schizophrenia and other psychoses & 3,854 & 2,653 & 68.8 \\
\hline Sleep wake disorders & 10,562 & 5,574 & 52.8 \\
\hline Physical diagnostic categories & 7,812 & 3,769 & 48.3 \\
\hline
\end{tabular}

medication for $\geq 90$ days, and 29,909 (39.5\%) of this group received PP for $\geq 90$ days.

\section{Demographics of Children Receiving Interclass PP}

For the years 2012-2015, the overall rate of children who were dispensed at least 1 psychotropic medication for $\geq 90$ days and who were treated with interclass PP was 39.5\% (Table 1). This rate was slightly lower for children aged $0-5$ years $(32.1 \%$, $P<0.001$ ) and higher for children aged between 6-11 years (42.2\%, $P<0.001$ ). Children with bipolar disorder had the highest PP rate (73.1\%) of any other behavioral health diagnosis, followed by DMDD (68.9\%) and schizophrenia (68.8\%).

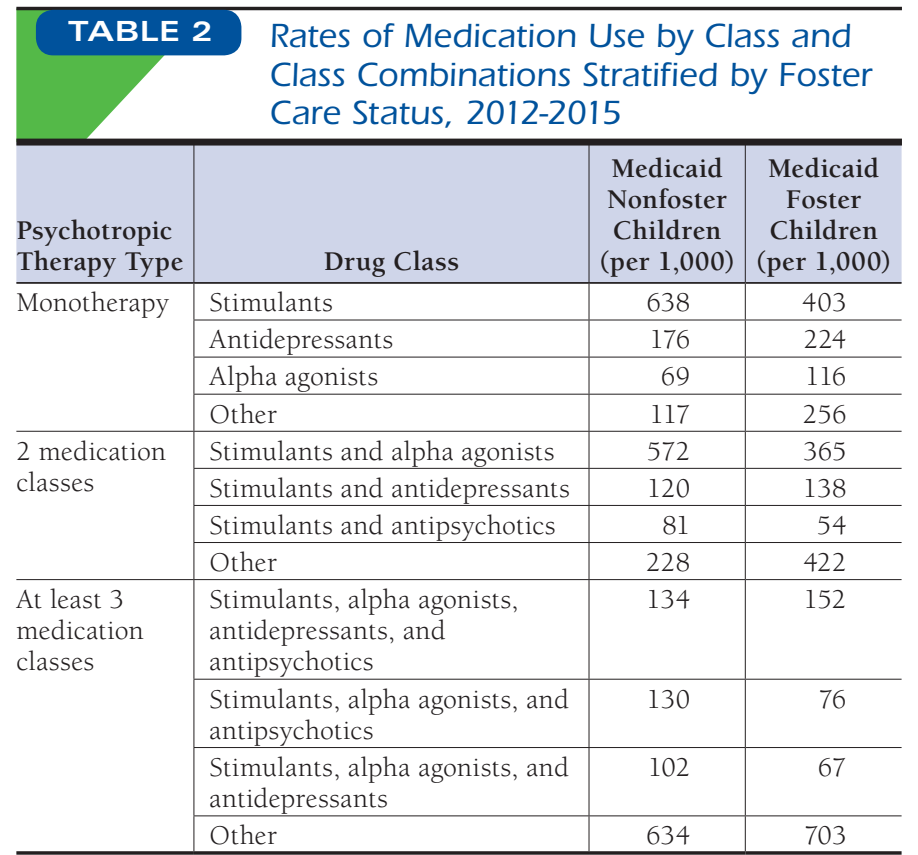

Note: These numbers represent the number of children per 1,000 children treated with at least 90 days of psychotropic medications during 2012-2015 and without seizure disorders with (a) no psychotropic polypharmacy and only treated with 1 psychotropic medication, (b) interclass PP with exactly 2 psychotropic medications, and (c) interclass PP with 3 or more psychotropic medications.

$P P=$ psychotropic polypharmacy.

Over the 4 study years, $27.5 \%$ of children treated with interclass PP received no associated psychotherapy. Children in foster care received interclass PP significantly more often than the overall Medicaid population $(62.6 \%, P<0.001)$.

As shown in Table 2, stimulants were by far the most common psychotropic medication dispensed to children on Kentucky Medicaid. Stimulants were the most common class of psychotropic medication for children without any PP treatment and were included in the most common combinations of interclass PP for children with 2 concurrent classes of medications and with 3 or more concurrent classes of medications.

\section{Factors Associated with Interclass PP}

As shown in Table 3 (adjusted), being in foster care (odds ratio $[O R]=1.71,95 \% \mathrm{CI}=1.58,1.84 ; \mathrm{P}<0.001)$; having a bipolar disorder $(\mathrm{OR}=2.24 ; 95 \% \mathrm{CI}=2.11,2.38 ; \mathrm{P}<0.001)$; mood disorder not otherwise specified $(\mathrm{OR}=1.11,95 \% \mathrm{CI}=1.04,1.17, \mathrm{P}<0.001)$; ASD $(\mathrm{OR}=1.17 ; 95 \% \mathrm{CI}=1.08,1.26 ; \mathrm{P}<0.001)$; or the presence of each additional psychiatric comorbid condition $(\mathrm{OR}=1.8$, $95 \% \mathrm{CI}=1.74,1.85 ; \mathrm{P}<0.001)$ increased the odds of receiving interclass PP. However, children whose race was reported to be black $(\mathrm{OR}=0.72,95 \% \mathrm{CI}=0.67,0.76 ; \mathrm{P}<0.001)$ had lower levels of PP in comparison with children who were reported as white. Children with depression $(\mathrm{OR}=0.49,95 \% \mathrm{CI}=0.47,0.52$; $P<0.001)$; impulse control disorder $(\mathrm{OR}=0.64,95 \% \mathrm{CI}=0.60$, 


\begin{tabular}{|c|c|c|}
\hline \multicolumn{3}{|c|}{$\begin{array}{l}\text { Factors Associated with Interclass PP } \\
\text { Among Children Enrolled in Kentucky } \\
\text { Medicaid with at Least } 90 \text { Days of } \\
\text { Psychotropic Medication Therapy and } \\
\text { No Seizure Disorders Between } 2012 \\
\text { and } 2015\end{array}$} \\
\hline Predictors & OR $(95 \% \mathrm{CI})$ & \multirow{2}{*}{$\begin{array}{c}P \text { Value } \\
<0.001\end{array}$} \\
\hline Gender, male & $1.28 \quad(1.23,1.33)$ & \\
\hline \multicolumn{3}{|l|}{ Age category } \\
\hline $0-5$ years & Reference & \\
\hline $6-11$ years & $1.58 \quad(1.5,1.67)$ & $<0.001$ \\
\hline $12-17$ years & $1.25 \quad(1.17,1.32)$ & $<0.001$ \\
\hline Foster care & $1.71 \quad(1.58,1.84)$ & $<0.001$ \\
\hline Nonmetropolitan residence $^{a}$ & $0.95 \quad(0.91,0.98)$ & 0.003 \\
\hline \multicolumn{3}{|l|}{ Race category } \\
\hline White & Reference & \\
\hline Black & $0.72 \quad(0.67,0.76)$ & $<0.001$ \\
\hline Other & $1.01 \quad(0.90,1.12)$ & 0.869 \\
\hline Not provided & $1.24 \quad(1.19,1.3)$ & $<0.001$ \\
\hline \multicolumn{3}{|l|}{ Psychiatric diagnostic categories } \\
\hline Attention deficit disorders & Reference & \\
\hline Schizophrenia and other psychoses & $0.91 \quad(0.83,1.01)$ & 0.069 \\
\hline Bipolar disorder & $2.24 \quad(2.11,2.38)$ & $<0.001$ \\
\hline Mood disorder NOS & $1.11 \quad(1.04,1.17)$ & $<0.001$ \\
\hline Depression & $0.49 \quad(0.47,0.52)$ & $<0.001$ \\
\hline $\begin{array}{l}\text { Disruptive mood dysregulation } \\
\text { Disorder }\end{array}$ & $1.13(1.04,1.23)$ & 0.003 \\
\hline Conduct disorder & $(0.7,0.82)$ & $<0.001$ \\
\hline Oppositional defiant disorder & $0.98 \quad(0.93,1.04)$ & 0.471 \\
\hline Autism PDD NOS & $1.17 \quad(1.08,1.26)$ & $<0.001$ \\
\hline Anxiety and trauma-related disorders & $0.73 \quad(0.7,0.77)$ & $<0.001$ \\
\hline Other mental disorders & $0.76 \quad(0.72,0.8)$ & $<0.001$ \\
\hline Other neurodevelopmental disorders & $0.72 \quad(0.68,0.76)$ & $<0.001$ \\
\hline Impulse control disorder & $0.64 \quad(0.60,0.67)$ & $<0.001$ \\
\hline Sleep wake disorders & $0.89 \quad(0.84,0.94)$ & $<0.001$ \\
\hline Covered months & $1.01 \quad(1.01,1.02)$ & $<0.001$ \\
\hline Total number of psychiatric diagnoses & $1.8 \quad(1.74,1.85)$ & $<0.001$ \\
\hline \multicolumn{3}{|c|}{$\begin{array}{l}\text { Note: Total sample, } n=67,798 \text {. Children with seizure disorders were removed from } \\
\text { the sample, with 67,827 observations remaining. } \\
\text { aNonmetropolitan was defined as county of residence having an RUCC code of 4-9. } \\
C I=\text { confidence interval; NOS=not otherwise specified; OR=odds ratio; } \\
P D D=\text { pervasive developmental disorders; } P P=\text { psychotropic polypharmacy; } \\
\text { RUCC=2013 Rural-Urban Continuum Codes. }\end{array}$} \\
\hline
\end{tabular}

0.67; $P<0.001$ ); or several other diagnoses were less likely to be treated with interclass PP for $\geq 90$ consecutive days.

\section{Factors Associated with Interclass PP Treatment Length}

The results for predicting the length of treatment with PP were similar to the predictors for treatment with any interclass PP. As seen in Table 4 (adjusted), males had more covered months with PP compared with females (beta $=1.01$, 95\% CI $=0.87$, $1.16, P<0.001)$. Children aged 6-11 years had more covered months with PP compared with children aged 0-5 years

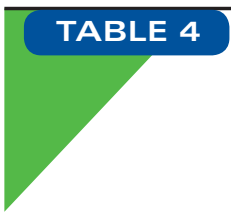

Predictors of Length of Interclass PP Treatment, Measured in Months, Among Children Enrolled in Kentucky Medicaid with at Least 90 Days of Psychotropic Medication Therapy and No Seizure Disorders Between 2012 and 2015

\begin{tabular}{|c|c|c|}
\hline Predictors of PP Treatment Length & Beta Values $(95 \% \mathrm{CI})$ & $P$ Value \\
\hline Gender, male (reference: female) & $1.01 \quad(0.87,1.16)$ & $<0.001$ \\
\hline \multicolumn{3}{|l|}{ Age category } \\
\hline $0-5$ years & Reference & \\
\hline $6-11$ years & $3.08 \quad(2.87,3.29)$ & $<0.001$ \\
\hline $12-17$ years & $1.60 \quad(1.37,1.83)$ & $<0.001$ \\
\hline Foster care & $1.81 \quad(1.52,2.11)$ & $<0.001$ \\
\hline Nonmetropolita & $-0.4 \quad(-0.54,-0.26)$ & $<0.001$ \\
\hline \multicolumn{3}{|l|}{ Race category } \\
\hline White & Reference & \\
\hline Black & $-1.37(-1.61,-1.12)$ & $<0.001$ \\
\hline Other & $-0.82(-1.23,-0.40)$ & $<0.001$ \\
\hline Not pr & $1.33(1.16,1.51)$ & $<0.001$ \\
\hline \multicolumn{3}{|l|}{ Psychiatric diagnostic categories } \\
\hline Attention deficit disorders & Reference & \\
\hline Schizophrenia and other psych & $-1.06(-1.42,-0.70)$ & $<0.001$ \\
\hline Bipolar disorder & $3.62 \quad(3.38,3.86)$ & $<0.001$ \\
\hline Mood disorder NOS & $0.56 \quad(0.33,0.80)$ & $<0.001$ \\
\hline Depression & $-3.32(-3.54,-3.10)$ & $<0.001$ \\
\hline Disruptive mood dysregulation disorder & $0.81 \quad(0.5,1.12)$ & $<0.001$ \\
\hline Conduct disorder & $-1.32(-1.62,-1.03)$ & $<0.001$ \\
\hline Oppositional defiant disorder & $-0.17(-0.39,0.05)$ & 0.136 \\
\hline Autism PDD NOS & $2.05 \quad(1.75,2.34)$ & $<0.001$ \\
\hline Anxiety and trauma-related disor & $-1.29(-1.48,-1.09)$ & $<0.001$ \\
\hline Other mental disorders & $-0.96(-1.18,-0.74)$ & $<0.001$ \\
\hline Other neurodevelopmental disorders & $-0.49(-0.71,-0.27)$ & $<0.001$ \\
\hline Impulse control disorder & $-2.07(-2.28,-1.85)$ & $<0.001$ \\
\hline Sleep wake disorders & $-0.53(-0.77,-0.29)$ & $<0.001$ \\
\hline Total number of psychiatric diagnoses & $2.49 \quad(2.36,2.61)$ & $<0.001$ \\
\hline \multicolumn{3}{|c|}{$\begin{array}{l}\text { Note: Total sample, } n=67,798 \text {. Children with seizure disorders were removed from } \\
\text { the sample, with } 67,827 \text { observations remaining. } \\
{ }^{a} \text { Nonmetropolitan was defined as county of residence having an RUCC code of 4-9. }\end{array}$} \\
\hline
\end{tabular}

(beta $=3.08,95 \% \mathrm{CI}=2.87,3.29 ; P<0.001$ ), and those aged 12-17 years also had more covered months, although to a lesser degree (beta $=1.60,95 \% \mathrm{CI}=1.37,1.83 ; P<0.001$ ). Being in foster care (beta $=1.81,95 \% \mathrm{CI}=1.52,2.11 ; P<0.001$ ) and having a bipolar disorder (beta $=3.62,95 \% C I=3.38,3.86, P<0.001$ ) and ASD (beta $=2.05,95 \% \mathrm{CI}=1.75,2.34 ; P<0.001$ ) increased the number of months of receiving interclass PP. Children with depression (beta $=-3.32,95 \% \mathrm{CI}=-3.54,-3.10 ; \mathrm{P}<0.001$ ) or impulse control disorder (beta $=-2.07,95 \% \mathrm{CI}=-2.28,-1.85$, $P<0.001)$ were treated for fewer months with interclass PP. However, as the number of additional psychiatric comorbidities 
increased, the length in months of PP treatment increased (beta $=2.49,95 \% \mathrm{CI}=2.36,2.61 ; P<0.001$ ), as well.

\section{Discussion}

The use of psychotropic medication for children and youth, including PP, has increased over recent years. This study provides new data from a statewide sample of children receiving Kentucky Medicaid services and fills a gap in the literature by using recent data (2012-2015) that includes children aged 0-17 years stratified by age, gender, race, diagnostic category, and foster care.

The overall rate of children on psychotropic medication for $\geq 90$ days who were treated with interclass PP was 39.5\%. This rate was slightly lower for children aged $0-5$ years $(32.1 \%$, $P<0.001)$ and higher for children aged 6-11 years (42.2\%, $P<0.001)$. Children with bipolar disorder had the highest PP rate $(73.1 \%)$ of any other behavioral health diagnosis, followed by DMDD (68.9\%) and schizophrenia (68.8\%). Children in foster care received interclass PP significantly more often than the overall population $(62.6 \%, P<0.001)$. A substantial proportion of children on Kentucky Medicaid with ASD, ADHD, or depressive disorders were exposed to PP, and these rates are markedly higher for those in foster care.

The proportion (39.5\%) of children enrolled in Kentucky Medicaid exposed to PP is higher than national averages., ${ }^{9,13}$ Among children aged more than 6 years, this rate of PP is almost twice that reported by Comer et al. (2010) and 3 times that reported by Chen et al. (2011).9,13 Importantly, in our study, children aged 6-11 years had the greatest likelihood of longer duration of interclass PP. Differences in the definitions of polypharmacy and the populations studied make comparisons difficult, but children aged between 6 and 11 years are a vulnerable population deserving of further study.

Children in foster care had significantly higher rates (62.6\%) and more covered months with PP compared with children who were not in foster care. The rates are less than those reported by Zito et al. (2008) for children aged birth-19 years in Texas who were in foster care (72.5\%). ${ }^{22}$ Again, methodological differences make comparisons difficult, but the literature suggests that children in foster care are in need of careful monitoring by specialized mental health providers to ensure that they are receiving appropriate, evidence-based care..$^{22-26}$

Children who were reported with race as black had less PP and shorter durations of PP compared with children reported as white. It is not clear whether this reflects an access issue, treatment bias, or some protective factor that has not been identified. Other studies of polypharmacy in children have not reported on differences by race. This is an important area in which to focus future studies.

Throughout 2012-2015, about one quarter of the children treated with interclass PP received no associated psychotherapy (27.5\%) within the 4-year period. Also, less than 50\% of this sample receiving interclass PP received psychotherapy in any given year. ${ }^{5}$ The quality measure from the Healthcare Effectiveness Data and Information Set (HEDIS), a widely used set of health care performance standards, requires that behavioral health interventions be instituted before starting treatment with antipsychotics for children. ${ }^{27}$ While no specific HEDIS measure exists for other psychotropic medication or for PP, first-line psychosocial interventions are indicated.

The type and number of psychiatric diagnoses influence the prevalence and duration of PP. Diagnoses of bipolar disorder, mood disorder not otherwise specified, or ASD are significant predictors of interclass PP in our study. PP increases with reported number of psychiatric comorbidities. These findings are consistent with previous reports of increases in PP for those children with greater impairment., ${ }^{9,28}$

Stimulants and alpha agonists were the most common 2-class PP combinations and, along with antipsychotics, the most common 3-class PP combinations. This pattern suggests that problems associated with ADHD and disruptive behaviors are driving the use of multiple psychotropic medications in our population, which is of concern in this population, since research has shown that there are other factors that may contribute to attention problems in children living in poverty that may mimic ADHD but would benefit from nonpharmacological therapies..$^{29-31}$

Our study supplements national reports of increased psychotropic medication use and PP in youth and raises concerns about the nature of current mental health treatment of children and adolescents. There is little evidence to support the efficacy of PP in children. ${ }^{7}$ Pharmacokinetic and pharmacodynamic drug interactions may lead to adverse effects in children treated with multiple psychotropics. ${ }^{\top}$ More controlled trials of psychotropic augmentation in children are needed to assess the associated risks and benefits of PP, such as the augmentation of stimulants with antipsychotic medication in the Treatment of Severe Childhood Aggression (TOSCA) studies. ${ }^{32}$

Much remains unknown about the long-term effects of monotherapy, as well as the effects of PP, on the developing brains of children. In addition, the cost of antipsychotic medications and general PP can have a significant effect on state Medicaid budgets. For example, as much as $70 \%-80 \%$ of total health care costs for adult patients with antipsychotic medication polypharmacy were related to drugs. ${ }^{33}$ Increased costs associated with adverse effects, emergency department utilization, and length of stay for inpatient hospitalizations related to PP represent possible cost burdens for adults and children, in addition to representing quality of care issues.

Provider practice styles and behaviors involving PP require attention. In general, the rate of psychiatric treatment involving psychotropic drugs has increased over the last decade, and our study confirmed national findings that many children with PP do not receive psychosocial therapy. ${ }^{3}$ Given the implications of 
disruptive behavior and aggression in children, these findings are contrary to professional guidelines that suggest the use of evidence-based psychosocial therapy as a first-line approach to treating these conditions. ${ }^{34,35}$ Questions of diagnostic inflation and "treatment creep" have been raised by those criticizing modern psychiatry's diagnostic systems and reliance on pharmacotherapy. ${ }^{36}$ Providers mention lack of alternative treatment resources and external expectations of families or systems to reduce symptoms as a reason for using antipsychotic medications in youth. ${ }^{37}$ A system change focusing on judicious prescribing practices is necessary to balance the use of psychotropic medication and psychosocial therapy to ensure rational prescribing. ${ }^{38}$

System solutions to the problem of PP in children include increased access to high-quality psychosocial care and evidence-based treatments. Collaborative care models integrating mental health into primary care may help address unmet needs in pediatric mental health. ${ }^{39}$ It may be anticipated that the growth of electronic health systems and the ability to manage "big data" may result in more effective care coordination and minimally burdensome real-time monitoring to identify children who are being prescribed psychotropic medications in worrisome patterns, such as off-label, polypharmacy, without psychosocial care, and without appropriate monitoring and surveillance). For example, some states have used systems such as the Comprehensive Neuroscience program to track for signs of worrisome prescribing. ${ }^{22}$ Televideo consults between providers and medication reviews have also been shown to reduce rates of worrisome psychotropic medication prescribing (including polypharmacy) for children in foster care and Medicaid, ${ }^{40}$ emphasizing the importance of care coordination in addressing this issue.

In addition, disruptive behaviors and aggression are influenced by a number of biopsychosocial issues, such as family poverty, parent education, parent and youth substance abuse, and environmental characteristics (such as chaos), that require investment in the communities where children and families live. Improved case worker, provider, and consumer education on psychotropic medication use in children may result in improvements in the informed consent process and more rational medication use. ${ }^{26}$ Also, trauma-informed training for all individuals working with children in the foster care system may result in a greater understanding of the challenges facing these children and possible benefits of nonpharmaceutical treatment options. ${ }^{41,42}$

Future directions for research include developing and implementing plans to improve the rational use of psychotropic medications for children enrolled in Kentucky Medicaid, including those in foster care. Such a plan will likely involve ways to improve access to evidence-based psychosocial therapies for children; education for families, youth, health care providers, and case workers; and communication between patients, families, providers, and experts in the field. Ways to improve access to high quality mental health specialists for all children are needed, especially for those who are most vulnerable, such as children in foster care and those receiving Medicaid services. Strategies may be tailored to geographic differences or sociodemographic factors.

\section{Limitations}

This study has some limitations to consider. The inability to address the appropriateness of PP; the quality, timing, and duration of psychosocial care; the severity of the symptoms; and the use of data from only Kentucky Medicaid claims may or may not reflect the prescribing patterns in other states. The use of administrative claims data also presents several limitations, including lack of information about treatment without a formal diagnosis, limited diagnostic data with only 4 listed for each claim, and the potential for errors in billing codes. The accuracy of the diagnoses can be questioned given that the data were extracted from administrative claims.

Similarly, data on race was self-reported and not required, with $22 \%$ of the sample not reporting race. Also, claimsbased approaches to detecting psychotherapy may not have adequately identified all services that children receive, such as those provided in schools and residential care facilities. In addition, we only reported on children who had continuous Medicaid coverage for $>90$ days. Children who go in and out of the Medicaid system may be at risk for receiving fragmented care and forming unique patterns of medication usage. More research is needed to understand factors associated with gaps in Medicaid coverage and how to ensure that eligible children have continuous coverage.

Our study used definitions of continuous enrollment and $\geq 90$ days of consecutive concomitant psychotropic medication use as indicated by HEDIS, which, in 2015, addressed the issue of antipsychotic polypharmacy. ${ }^{27}$ While these criteria are stricter than previously reported studies and affected our reported rates, the use of standardized definitions would allow for more valid comparison among studies in the future. Even with our stricter definition of concomitant use, our rates were higher than those previously reported.

\section{Conclusions}

This study presents findings from 2012-2015 Kentucky Medicaid claims data that fill a gap in the literature by providing more current information on PP prescribing trends in children from a large statewide dataset. We also extended previous studies by including data on race and on children aged $<6$ years. Stimulants were the most frequently dispensed psychotropic medication class alone and in combination with other psychotropic medications. More research is needed in this area to determine the appropriateness of using stimulants in combination with other psychotropic medications in children. 
Current PP trends are concerning, and continued vigilance and empirical evidence are needed to ensure that appropriate prescribing practices are used in combination with psychosocial therapies and that careful monitoring is employed to achieve the safest and best outcomes for children with mental health disorders, especially those living in poverty. Finally, our data showed that children who were black experienced lower levels of PP compared with children who were white. It is not known if this reflects differences in access and appropriateness of care. More research in this area is needed to address potential health disparities in PP associated with race.

\section{Authors}

W. DAVID LOHR, MD; YANA FEYGIN, MS; MICHELLE

STEVENSON, MD, MS; MICHAEL J. SMITH, MD, MSCE; JOHN MYERS, PhD, MPH; CHARLES WOODS, MD, MS; and DEBORAH WINDERS DAVIS, PhD, University of Louisville, School of Medicine, Department of Pediatrics, Child and Adolescent Health Research Design and Support (CAHRDS), Louisville, Kentucky. LIZA CREEL, PhD, MPH, University of Louisville, School of Public Health and Information Sciences, Department of Health Management and Systems Sciences, Louisville, Kentucky. GIL LIU, MD, MS, University of Louisville, School of Medicine, Department of Pediatrics, Child and Adolescent Health Research Design and Support (CAHRDS), Louisville, Kentucky, and Kentucky Cabinet for Health and Family Services, Department of Medicaid Services, Frankfort.

AUTHOR CORRESPONDENCE: Deborah Winders Davis, PhD, Department of Pediatrics, University of Louisville, 571 S. Floyd St., Ste. 412, Louisville, KY 40202. Tel.: 502.588.0846;

E-mail:deborah.davis@louisville.edu.
3. Olfson M, Blanco C, Wang S, Laje G, Correll CU. National trends in the mental health care of children, adolescents, and adults by office-based physicians. JAMA Psychiatry. 2014;71(1):81-90.

4. Medicaid and CHIP Payment and Access Commission. Chapter 5. Use of psychotropic medications among Medicaid beneficiaries. In: Report to Congress on Medicaid and CHIP. March 2014. Available at: https://www. macpac.gov/publication/report-to-the-congress-on-medicaid-and-chip-314/ Accessed June 5, 2018.

5. Davis DW, Smith MJ, Creel L, et al. Medication prescribing to children insured by Kentucky Medicaid annual report June 2017. Louisville, KY: University of Louisville; 2017.

6. Cohen E, Hall M, Lopert R, et al. High-expenditure pharmaceutical use among children in Medicaid. Pediatrics. 2017;140(3).

7. Jureidini J, Tonkin A, Jureidini E. Combination pharmacotherapy for psychiatric disorders in children and adolescents: prevalence, efficacy, risks and research needs. Paediatr Drugs. 2013;15(5):377-91.

8. Linton D, Barr AM, Honer WG, Procyshyn RM. Antipsychotic and psychostimulant drug combination therapy in attention deficit/hyperactivity and disruptive behavior disorders: a systematic review of efficacy and tolerability. Curr Psychiatry Rep. 2013;15(5):355.

9. Comer JS, Olfson M, Mojtabai R. National trends in child and adolescent psychotropic polypharmacy in office-based practice, 1996-2007. J Am Acad Child Adolesc Psychiatry. 2010;49(10):1001-10.

10. Logan SL, Nicholas JS, Carpenter LA, King LB, Garrett-Mayer E, Charles JM. High prescription drug utilization and associated costs among Medicaid-eligible children with autism spectrum disorders identified by a population-based surveillance network. Ann Epidemiol. 2012;22(1):1-8.

11. Murray ML, Hsia Y, Glaser K, et al. Pharmacological treatments prescribed to people with autism spectrum disorder (ASD) in primary health care. Psychopharmacology (Berl). 2014;231(6):1011-21.

12. Feinstein JA, Feudtner C, Valuck RJ, Kempe A. The depth, duration, and degree of outpatient pediatric polypharmacy in Colorado fee-for-service Medicaid patients. Pharmacoepidemiol Drug Saf. 2015;24(10):1049-57.

13. Chen H, Patel A, Sherer J, Aparasu R. The definition and prevalence of pediatric psychotropic polypharmacy. Psychiatr Serv. 2011;62(12):1450-55.

14. Kreider AR, Matone M, Bellonci C, et al. Growth in the concurrent use of antipsychotics with other psychotropic medications in Medicaid-enrolled children. J Am Acad Child Adolesc Psychiatry. 2014;53(9):960-70.e2.

15. Lohr WD, Chowning RT, Stevenson MD, Williams PG. Trends in atypical antipsychotics prescribed to children six years of age or less on Medicaid in Kentucky. J Child Adolesc Psychopharmacol. 2015;25(5):440-43.

16. Annie E. Casey Foundation. 2017 Kids count data book: state trends in child well-being. Available at: http://www.aecf.org/m/resourcedoc/aecf2017kidscountdatabook.pdf. Accessed June 5, 2018.

17. Burcu M, Zito JM, Safer DJ, et al. Concomitant use of atypical antipsychotics with other psychotropic medication classes and the risk of type 2 diabetes mellitus. J Am Acad Child Adolesc Psychiatry. 2017;56(8):642-51.

18. Martin A, Van Hoof T, Stubbe D, Sherwin T, Scahill L. Multiple psychotropic pharmacotherapy among child and adolescent enrollees in Connecticut Medicaid managed care. Psychiatr Serv. 2003;54(1):72-77.

19. dosReis S, Zito JM, Safer DJ, Gardner JF, Puccia KB, Owens PL. Multiple psychotropic medication use for youths: a two-state comparison. J Child Adolesc Psychopharmacol. 2005;15(1):68-77.

20. Nguyen T, Hellebuyck M, Halpern M, Fritze D. The state of mental health in America 2018. Mental Health America. Available at: https://www. sprc.org/sites/default/files/resource-program/2018\%20The\%20State\%20 of $\% 20 \mathrm{MH} \% 20 \mathrm{in} \% 20$ America $\% 20-\% 20 \mathrm{FINAL} \% 20 \% 28002 \% 29$.pdf. Accessed June 5, 2018. 
21. U.S. Department of Health and Human Services, Health Resources and Services Administration, National Center for Health Workforce Analysis. The U.S. health workforce chartbook part IV: behavioral and allied health. 2013. Rockford, MD. Available at: https://bhw.hrsa.gov/sites/default/files/ bhw/nchwa/chartbookpart4.pdf. Accessed June 5, 2018.

22. Zito JM, Safer DJ, Sai D, et al. Psychotropic medication patterns among youth in foster care. Pediatrics. 2008;121(1):e157-63.

23. Alavi Z, Calleja NG. Understanding the use of psychotropic medications in the child welfare system: causes, consequences, and proposed solutions. Child Welfare. 2012;91(2):77-94.

24. dosReis S, Tai MH, Goffman D, Lynch SE, Reeves G, Shaw T. Age-related trends in psychotropic medication use among very young children in foster care. Psychiatr Serv. 2014;65(12):1452-57.

25. Fontanella CA, Warner LA, Phillips GS, Bridge JA, Campo JV. Trends in psychotropic polypharmacy among youths enrolled in Ohio Medicaid, 20022008. Psychiatr Serv. 2014;65(11):1332-40.

26. Mackie TI, Hyde J, Palinkas LA, Niemi E, Leslie LK. Fostering psychotropic medication oversight for children in foster care: a national examination of states' monitoring mechanisms. Adm Policy Ment Health. 2017;44(2):243-57.

27. National Committee for Quality Assurance. HEDIS 2015 measures. Available at: http://www.ncqa.org/hedis-quality-measurement/hedis-measures/hedis-archives. Accessed June 5, 2018.

28. Safer DJ, Zito JM, DosReis S. Concomitant psychotropic medication for youths. Am J Psychiatry. 2003;160(3):438-49.

29. Al Ghriwati N, Langberg JM, Gardner W, et al. Impact of mental health comorbidities on the community-based pediatric treatment and outcomes of children with attention deficit hyperactivity disorder. J Dev Behav Pediatr. 2017;38(1):20-28.

30. Duncan GJ, Ziol-Guest KM, Kalil A. Early-childhood poverty and adult attainment, behavior, and health. Child Dev. 2010;81(1):306-25.

31. Robinson JB, Burns BM, Davis DW. Maternal scaffolding and attention regulation in children living in poverty. J Appl Dev Psychol. 2009;30:82-91.
32. Aman MG, Bukstein OG, Gadow KD, et al. What does risperidone add to parent training and stimulant for severe aggression in child attention-deficit/ hyperactivity disorder? J Am Acad Child Adolesc Psychiatry. 2014;53(1):47-60.el.

33. Valuck RJ, Morrato EH, Dodd S, et al. How expensive is antipsychotic polypharmacy? Experience from five U.S. state Medicaid programs. Curr Med Res Opin. 2007;23(10):2567-76.

34. Correll CU, Manu P, Olshanskiy V, Napolitano B, Kane JM, Malhotra AK Cardiometabolic risk of second-generation antipsychotic medications during first-time use in children and adolescents. JAMA. 2009;302(16):1765-73.

35. Scotto Rosato N, Correll CU, Pappadopulos E, Chait A, Crystal S, Jensen PS. Treatment of maladaptive aggression in youth: CERT guidelines II. Treatments and ongoing management. Pediatrics. 2012;129(6):e1577-86.

36. Frances A. Saving Normal: An Insider's Revolt Against Out-of-Control Psychiatric Diagnosis, DSM-5, Big Pharma, and the Medicalization of Ordinary Life. New York: William Morrow; 2013.

37. Lohr WD, Brothers KB, Davis DW, et al. Providers' behaviors and beliefs on prescribing antipsychotic medication to children: a qualitative study. Community Ment Health J. 2018;54(1):17-26.

38. Grudnikoff E, Bellonci C. Deprescribing in child and adolescent psychiatry-a sorely needed intervention. Am J Ther. 2017;24(1):el-e2.

39. Sarvet B, Gold J, Bostic JQ, et al. Improving access to mental health care for children: the Massachusetts Child Psychiatry Access Project. Pediatrics. 2010;126(6):1191-200.

40. Hilt RJ, Barclay RP, Bush J, Stout B, Anderson N, Wignall JR. A statewide child telepsychiatry consult system yields desired health system changes and savings. Telemed J E Health. 2015;21(7):533-37.

41. Forkey H, Szilagyi M. Foster care and healing from complex childhood trauma. Pediatr Clin North Am. 2014;61(5):1059-72.

42. Schilling S, Fortin K, Forkey H. Medical management and traumainformed care for children in foster care. Curr Probl Pediatr Adolesc Health Care. 2015;45(10):298-305. 


\section{APPENDIX A Definitions and Codes Used to Construct Psychiatric Diagnostic Categories}

Categories and Diagnoses

Schizophrenia and other psychotic processes

Schizophrenia and schizoaffective disorder

Delusional disorders

Other nonorganic psychoses

Mood disorders total

Depressive disorders (listed below)

Bipolar and related disorders

Mood disorder NOS

Disruptive mood dysregulation disorder

Depressive disorders

Major depressive disorder and other depressive

disorders

Autism spectrum disorders

Other neurodevelopmental disorders

Intellectual disability

Tic disorders

Stereotypical movement disorder

Developmental delays

Disruptive behavior disorders

Conduct disorders

Attention deficit disorder

Oppositional defiant disorder

Anxiety and trauma-related disorders

Anxiety disorders

PTSD and acute stress disorder

OCD and related disorders

Adjustment disorders

Reactive attachment disorder

Other mental disorders

Mental disorders conditions classified

Disturbance emotions childhood adolescence

Feeding and eating disorders

Personality disorders

Syndromes elsewhere unclassified

Sexual and gender identity disorders

Dissociative disorders

Somatic symptom and related disorders

Sleep-wake disorders

mpulse control

Intermittent explosive disorder and impulse control

Physical diagnostic categories

Seizure epilepsy

Other convulsions

Posttraumatic seizures

ICD-9/10-CM = International Classification of Diseases, Ninth/Tenth Revision, Clinical Modification.

\section{ICD-9-CM Codes}

296.00-296.10, 296.40-296.89, 301.13

296.9

296.99

296.20-296.36, 300.4, 311, 625.4

299.xx

315.xx

314.xx

313.81

300.00-300.29, 309.21, 301.4, 312.23

308.3, 309.81, 309.89, 309.9

$300.3,300.7,312.39$

309.9

313.89

293.xx, 294.xx

$313.9 \mathrm{x}$

$301.7,301.8 x, 301.9,301.0$

307.xx

$302.2-302.9$

$300.14,300.12,300.15,300.6$

$300.82,300.89$

$312.30-312.34,312.89,312.9$
ICD-10-CM Codes

\begin{tabular}{|l|l|}
\hline $295 . x x$ & $\begin{array}{l}\text { F20, F200-F205, F208, F2081, F2089, F209, } \\
\text { F25.0, F25.1 }\end{array}$ \\
\hline $297 . x$ & F22 \\
\hline $298 . x$ & F28, F23, F29 \\
\hline
\end{tabular}

F30.10-F30.4, F30.8, F30.9, F31.0-F31.9, F34.0

F06.3, F39

F34.8

F32.0-F32.5, F32.8, F32.9, F33.0-F33.3, F33.8

F33.9, F33.41, F33.42, F34.1, N94.3

F80.89, F84, F840, F842, F843, F845, F848, F849

\begin{tabular}{l|l} 
317.xx, 318.xx, 319.xx, 758 & Q909, F70-F73, F78, F79
\end{tabular}

\begin{tabular}{l|l}
\hline $307.20-307.23$ & F95, F950-F952, F958, F959
\end{tabular}

\begin{tabular}{|l|l|}
\hline 307.3 & F984 \\
\hline $315 . x x-307.23$ & F80, F8
\end{tabular}

F80, F80.81, F80.9, F81, F81.1, F81.2, F82, F88, F89

\begin{tabular}{|l|l}
312.81 & F91x except F913
\end{tabular}

F90x

F913

309.0, 309.24, 309.28, 309.3, 309.4, 309.89,

F40-F419, F93.0, F94.0

F430, F431-F4312, F43.8

F42, F45.22, F63.2, L98.1

F43, F432-F439

F938, F941, F942, F988

$307.1,307.50,307.51,307.52,307.53,307.59$

$301.0,301.1 x, 301.2 x, 301.3,301.5 x, 301.6$,

$780.52,780.54,307.45,307.46,307.47,327.21$,

$327.23,327.42,333.94,347.00,347.01,347.10$

F63-F632, F633, F638-F639

F53, F02-F062, F064, F068, F524

F939, F948, F989

F50x, F982, F9821, F9829, F983

F21, F34, F340, F341, F60-F609, F68-F69

F98.0, F98.1, F99

F52, F520-F522, F5221, F5222, F523

F5231-5232, F524-F526, F528, Ff29, F64-F66

F44.0-F44.7, F44.81, F44.89, F448-F449

F44.4-F44.7, F45, F450, F451, F452, F45.21, F4529,

F454, F4541, F4542, F458, F459, F488, F68.10

F51, F510, F5101-F5105, F5109, F511,

F5111-F5113, F5119, F513-F515, F518, F519,

G25.81, G47.00, G47.09, G47.10, G47.19,

G47.20-G47.26, G47.31, G47.33, G47.411, G47.419,

G47.429, G47.52, G47.8

G40

R56.9

R56.1 


\section{APPENDIX B Definitions of Drug Classifications}

\begin{tabular}{|c|c|c|c|c|}
\hline Antidepressants & Antidepressants & Antipsychotics & Benzodiazepines/ & Mood Stabilizers \\
\hline Adapin & Oleptro ER & Haldol Decanoate 100 & Anxiolytics/Hypnotics & Oxtellar XR \\
\hline Alplezin & Pamelor Parnate & Haloperidol & Oxazepam & Tegretol \\
\hline Amitril & Paroxetine & Haloperidol Decanoate & Phenobarbital & Tegretol XR \\
\hline Amitrip HCL/ & Paroxetine $\mathrm{HCL}$ & Haloperidol Decanoate 100 & Rozerem & Topamax \\
\hline Chlordiazepoxide & Paxl & Haloperidol Lactate & Temazepam & Topiram \\
\hline Amitriptyline & Pertofrane & lloperidone & Riazolam & Topiramate \\
\hline Amitriptyline $\mathrm{HCL}$ & Phenelzine Sulfate & lloperidone (Fanapt) & Zaleplon & Topiramate ER \\
\hline Amozapine & Phenelzine Sulfate & Invega & Zolpidem Tartrate & Trileptal \\
\hline Anafranil & Presamine & Invega Sustenna & Zolpidem Tartrate ER & Trokendi XR \\
\hline Asendin & Pristq & Latuda & Zolpimist & Valproate \\
\hline Aventyl & Pristiq ER & Loxpin & & Valproate Sodium \\
\hline Buderprion & Protriptyline HCL & Loxapine & Alpha Agonists & Valproic Acid \\
\hline Buderprion SR & Prozac & Lurasidone & Catapres & \\
\hline Buderprion XL & Remeron & Olanzapine & Catapres-TTS 1 & Stimulants \\
\hline Buproban & Sarafem & Olanzapine ODT & Catapres-TTS 2 & Adderell \\
\hline Bupropion & Sarna & Olanzapine-Fluoxetine $\mathrm{HCL}$ & Catapres-TTS 3 & Adderall XR \\
\hline Bupropion HCL & Sarna Sensitive & Orap & Clondine & Amphet ASP/Amphet/D- \\
\hline Bupropion HCL SR & Savella & Paliperdone & Clondine HCL & Amphet \\
\hline Burpropion XL & Selegiline & Paliperdone (Invega) & Clondine HCL ER & Amphetamine Salt Combo \\
\hline CDP \& Amitriptyline & Sertraline & Perphenazine & Guanfacine & Amphetmine/ \\
\hline Celexa & Sertraline $\mathrm{HCL}$ & Perphenazine \& Amitripyl & Guanfacine HCL & Dextroamphetamine \\
\hline Chlordiazepoxide and Amitrip & Serzone & Perphenazine $2 \mathrm{mg}$ w/Amitri & Guanfacine HCL ER & Atomoxetine \\
\hline Chlordiazepoxide/Amitrip & Silenor & Perphenazine 4 mg w/Amitri & Intuniv & Concerta \\
\hline Chlordiazepoxide-Amitrip & Sinequan & Perphenazine Amitriptylin & Kapvay & Cylert \\
\hline Chlordiazepoxide-Clidinium & SK-Amitriptyline & Perphenazine \& Amitript & Methyldopa & D-Amphetamine Sulfate \\
\hline Citalopram & $\begin{array}{l}\text { SK-Amitriptylıne } \\
\text { SK-Pramine }\end{array}$ & Perphenazine w/Amitrip & Methyldopa- & Daytrana \\
\hline Citalopram HBR & SK-Pramine & Perphenazine/Amitrip & Hydrochlorothiazide & Desoxyn \\
\hline Clomipramine $\mathrm{HCL}$ & Symbyax & Perphenazine-Amitriptyline & & Dexedrine \\
\hline Cymbalta & Symbyax & Prochloperazine & Mood Stabilizers & Dexmethylphenidate \\
\hline Despramine & Tofranil & Prochlorperazine & Carbamazepine & Dexmethylphenidate HCL \\
\hline & Tofranil-PM & Prochlorperazine Maleate & Carbamazepine ER & Dexmethylphenidate HCL ER \\
\hline $\begin{array}{l}\text { Despramine HCL } \\
\text { Desvenlafaxine }\end{array}$ & Tranylcypromine Sulfate & Quetiapine & Carbamazepine XR & Dextroamphetamine \\
\hline & Trazodone & Quetiapine Fumarate & Carbatro & Dextroamphetamine Sulfate \\
\hline Desyrel & Trazodone HCL & Risperdal & Carbatrol & Dextroamphetamine Sulfate \\
\hline Doxepin & Triavil & Risperdal Consta & Cibalith-S & ER \\
\hline Doxepin HCL & Trimipramine Maleate & Risperdal M-Tab & Depakene & Dextroamphetamine-Amphet \\
\hline Duloxetine & Tryptanol & Risperidone & $\begin{array}{l}\text { Depakene } \\
\text { Depakote }\end{array}$ & ER \\
\hline Duloxetine HCL & Venlafaxine & Risperidone ODT & $\begin{array}{l}\text { Depakote } \\
\text { Depakote ER }\end{array}$ & Dextrostat \\
\hline Effexor & $\begin{array}{l}\text { Venlaraxine } \\
\text { Venlafaxine HCL }\end{array}$ & Saphirs. & & Focalin \\
\hline Effexor XR & $\begin{array}{l}\text { Venlafaxine HCL } \\
\text { Venlafaxine } \mathrm{HCL}\end{array}$ & Saphirs & Depakote Sprinkle & Focalin XR \\
\hline Elavil & & Seroqel & Divalproex & Lisdexamfetamine \\
\hline Emsam & Vibryd & Seroquel XR & Divalproex Sodiumer & Lisdexamfetamine (Vynase) \\
\hline Endep & Vilazodone & Thioridazine & Epitol & Metadate \\
\hline Escitalopram & Vivactil & Thioridazine HCL & Epsom Salt & Metadate CD \\
\hline Escitalopram (Lexapro) & Wellbutrin & Thiothixene & Equatro & Metadate ER \\
\hline Escitalopramoxalate & Wellbutrin XL & Trifluoperazine & Equetro & Methamphetamine $\mathrm{HCL}$ \\
\hline Etrafon & Xenazin & Trifluoperazine HCL & Eskalith & Methylphenidate \\
\hline Fluoxetine DR & Xenazine & Zprasidone & Gabapentin & Methylphenidate ER \\
\hline Fluoxetine $\mathrm{HCL}$ & Zoloft & Ziprasidone HCL & Gralise & Methylphenidate HCL \\
\hline Fluvoxamine & Zoloft & Zyprexa & Keppra & Methylphenidate HCL CD \\
\hline Fluvoxamine Maleate & Antipsychotics & Zyprexa Zydis & Keppra XR & Methylphenidate LA \\
\hline Fluvoxamine Maleate ER & $\begin{array}{l}\text { Antipsycnotics } \\
\text { Abilify }\end{array}$ & & Lamictal & Methylphenidate SR \\
\hline Imipramine & Abilify Discmelt & Benzodiazepines/ & Lamictal (green) & Pemoline \\
\hline Imipramine HCL & Abilify Maintenia & Anxiolytics/Hypnotics & Lamictal (orange) & Procentra \\
\hline Imipramine Pamoate & AbIlity IMalntenla & Alprazolam & Lamictal ODT & Quillivant \\
\hline Isocarboxazid & Amitriptyline HCL/ & Alprazolam ER & Lamictal ODT (green) & Quillivant XR \\
\hline Janimine & Perphenazine & Alprazolam ODT & Lamictal ODT (orange) & Ritalin \\
\hline Lexapro & Amitriptyline/Perphenazine & Alprazolam XR & Lamictal XR & Ritalin LA \\
\hline Limbitrol & Aripiprazole & Ambien CR & Lamotrigine & Ritalin-SR \\
\hline $\begin{array}{l}\text { LImbitrol } \\
\text { Ludiomil }\end{array}$ & Asenapine & Ativan & Lamotrigineer & Strattera \\
\hline Ludiomil & Asenapine (Saphris) & Buspirone HCL & Levetiracetam & Vynase \\
\hline Luvox & Chlorpromazine & Chlordiazepoxide HCL & Levetiraceamer & Vyvanse \\
\hline Luvox CR & Chorpromazme & Clorazepate Dipotassium & Lithane & \\
\hline Maprotline & Chlorpromazine HCL & Diastat & Lithium & \\
\hline Maprotline HCL & Clozapine & Diastat Acudial & Lithium Carbonate & \\
\hline Marplan & Clozapine ODT & Diazepam & Lithium Citrate & \\
\hline Milnacipran & Clozaril & Eszopiclone & Lithobid & \\
\hline Mirtazapine & Fanapt & Flurazepam HCL & Lithonate & \\
\hline Nardil & Fazaclo & Hydroxyzine HCL & Lithotabs & \\
\hline Nefazodone & Fluphenazine & Hydroxyzine Pamoate & Lyrica & \\
\hline Nefazodone HCL & Fluphenazine Decanoate & Lorazepam & Magnesium Sulfate & \\
\hline Norpramin & Flupphenazine HCL & Lorzepamintensol & Neurontin & \\
\hline Nortriptyline & Geodon & Lunesta & Oxcarbazepine & \\
\hline Oleptro & Haldol & Midazolam HCL & Oxtellar & \\
\hline
\end{tabular}

